\title{
OPTIMALISASI PENGOPERASIAN INERT GAS SYSTEM (IGS) PADA SAAT BONGKAR MUAT
}

Dalmadi $^{1)}$, Dalsih Setiono ${ }^{2)}$

${ }^{1), 2)}$ Program Studi Teknika Akademi Pelayaran Niaga Indonesia dalmadi@akpelni.ac.id

\begin{abstract}
ABSTRAK
Turbo charger adalah suatu komponen yang dipasang pada kendaraan bermotor yang bertujuan untuk meningkatkan daya dari motor dengan melakukan penambahan rapat massa udara yang lebih banyak dibandingkan dengan cara pengisian biasa. Turbocharger terdiri dari sebuah turbin dan sebuah kompresor. Penelitian ini bertujuan untuk mengetahui pengaruh penggunaan Turbo Charger, Variasi derajat awal penyemprotan pompa injeksi $\left(5^{\circ}, 10^{\circ}, 15^{\circ}\right)$ sebelum TMA terhadap efisiensi pemakaian bahan bakar pada mesin DAIHATSU dan diperoleh salah satu cara pemakaian bahan bakar yang hemat dengan menggunakan Turbo Charger dengan memperoleh daya yang besar. Hasil penelitian ini menunjukkan bahwa ada interaksi antara pemakaian turbo charger dan derajat awal penyemprotan pompa injeksi terhadap waktu pemakaian bahan bakar yaitu penggunaan Turbo Charger tidak berpengaruh secara signifikan terhadap efisiensi bahan bakar pada mesim DAIHATSU dan Variasi derajat awal penyemprotan pompa injeksi berpengaruh secara signifikan terhadap efisiensi bahan bakar pada mesin DAIHATSU.

Berdasarkan hasil penelitian ini, dapat disarankan agar dilakukan penelitian lebih lanjut misalnya kendala pada turbo charger terhadap daya dan gas buang pada mesin DAIHATSU
\end{abstract}

Kata kunci: turbo Charger, Variasi, injeksi, Efisiensi

\section{Latar Belakang Masalah}

Kita telah mengetahui bahwa kapal merupakan salah satu 
sarana transportasi laut yang berperan penting dalam kegiatan sebagai penghubung antar negara,wilayah ataupun pulaupulau. Dalam melayani kebutuhan yang semakin meningkat, kapal tidak hanya disediakan dalam jumlah banyak, akan tetapi mengupayakan agar kapal tersebut siap pakai.

Pada kapal-kapal yang digerakkan dengan mesin diesel,dalam pemakaian bahan bakar harus dijaga sistemnya. Semua perusahaan pelayaran kapal-kapalnya yang tergabung dalam armada yang tidak beroperasi dengan baik, disebabkan tidak berfungsinya salah satu dari komponen mesin,yang mana pernah penulis alami selama praktek laut diatas kapal.Pengoperasian kapal tentunya juga perlu adanya perawatan yang rutin dari motor induk sebagai mesin penggerak utama,agar tidak terjadi delay atau keterlambatan kapal yang disebabkan kurangnya perawatan pada motor induk.

Dalam hal perawatan kapal harus diperhatikan agar kondisi kapal dalam keadaan baik dan aman,terutama sekali dalam perawatan motor induk sebagai mesin penggerak utama. Para masinis yang terlibat dalam perawatan ini menjadi faktor utama dalam pelaksanaanya sehingga pengoperasian kapal dapat berjalan dengan lancar.Salah satu peralatan pada motor induk atau motor diesel yang sangat berguna adalah injektor(pengabut bahan bakar),oleh karena itu perlu himbauan kepada seluruh masinis yang berada diatas kapal agar perlu adanya pemahaman bagaimana cara pencegahan dan penanggulangan pembakaran yang tidak sempurna dari motor induk,baik dari segi teknik perawatan maupun akibat dari tidak normalnya alat pengabut bahan bakar (injektor) tersebut pada motor induk diatas kapal,maka dari itu perawatan injektor harus selalu dijaga sehingga mesin induk dapat berjalan dengan baik dan lancar.Pada dasarnya perawatan injektor (pengabut bahan bakar) yang baik adalah melakukan perawatan sesuai jam 
kerja yang telah ditentukan didalam buku manual,dengan demikian dapat meningkatkan efektifitas serta keuntungan bagi pemilik-pemilik kapal,karena dengan penangan injektor (pengabut bahan bakar) yang baik dapat menekan biaya operasional kapal,disamping itu juga kondisi mesin itu sendiri.

\section{Pembahasan}

\section{A. Penyebab Kurang Optimalnya Kinerja Injektor Dalam Pengabutan Bahan Bakar.}

Injektor bekerja dengan mengabutkan bahan bakar ke dalam ruang pembakaran dengan bentuk kabut dan pada saat yang tepat terjadi langkah kompresi piston, dengan tujuan untuk memperoleh hasil pembakaran yang sempurna dan merata pada ruang silinder.

Ketika kapal sedang melaksanakan pelayaran, mesin induk bekerja secara terus menerus dan proses pembakaran akan terus terjadi, hal ini juga berpengaruh pada kinerja injektor yang terus bekerja melakukan pengabutan bahan bakar. Kondisi demikian dapat mengakibatkan gesekan pada komponen injektor dan menyebabkan terjadinya kelelahan pada bahan atau material dari injektor, sehingga pada suatu saat akan terjadi penurunan kerja dan timbul kerusakan dan keausan pada injektor. Hal ini disebabkan oleh beberapa hal seperti berikut:

1. Terjadi Penyumbatan Kotoran Pada Lubang Nozzle Dari Injektor:

Setiap lubang dari alat pengabut dibuat dengan diameter lubang tertentu. Apabila lubang dibuat terlalu kecil akan mengakibatkan mudahnya lubang tersebut tertutup kotoran.

Dari hasil observasi penelitian bahwa apabila kondisi lubang sudah terlalu besar akan mengakibatkan 
bahan bakar tidak mengabut keseluruhan akan tetapi ada yang menetes, dimana sisa pembakaran akan terus terbakar setelah pembakaran. Dengan demikian bahan bakar yang terbakar akan menimbulkan sisa-sisa kotoran yang berupa arang juga karbon-karbon, dan menumpuknya sisa-sisa kotoran tersebut akan menutup lubang pengabut apabila terjadi secara terus-menerus. Apabila hal tersebut dibiarkan maka lubang dari nozzle injektor akan tersumbat oleh kotoran dan mengakibatkan bahan bakar yang dikabutkan tidak bisa keluar

melalui lubang nozzle injektor. Hal ini sangat berpengaruh pada proses pembakaran yang ada dalam ruang silinder. Untuk mengatasi hal tersebut harus dilakukan perawatan secara rutin dan pengecekan pada injektor. Perawatan yang dilakukan meliputi dengan pengecekan satu per satu dari diameter lubang dengan menggunakan pin test. Apabila dalam pemeriksaan diameter lubang pengabut bahan bakar sudah tidak memenuhi standar yang sesuai Instruction ManualBook bisa dilakukan penggantian dengan nozzle yang baru untuk menjaga kualitas pengabutan.

2. Pegas (Spring) Penekan Jarum Tidak Bekerja Optimal: Pegas disini berfungsi untuk menyetel kerapatan jarum pada mulut pengabut. Jadi pegas digunakan untuk mengatur tingkat tekanan kerja yang akan disemprotkan melalui nozzle. Apabila pegas sudah mengalami kelelahan bahan, akan menyebabkan berkurangnya elastisitas pada pegas, akan berakibat berkurangya kerapatan jarum dan kurang sempurna atau tidak pas, sehingga berpengaruh pada tekanan bahan bakar yang akan dikabutkan menjadi tidak optimal. 
Hal diatas dapat disebabkan oleh keausan dari pegas yang bekerja terlalu lama dan dimungkinkan terjadi kelelahan bahan, oleh sebab itu harus dilakukan penggantian pegas dengan yang baru. Perawatan pada pegas sangat penting untuk mengurangi resiko turunnya tekanan bahan bakar yang dikabutkan, agar pada saat pegas menekan jarum dapat menghasilkan tekanan yang ditentukan sebesar 280 bar. Tekanan kerja sangat dibutuhkan untuk menghasilkan pengabutan yang merata pada ruang silinder, sehingga menghasilkan pembakaran yang sempurna. Hal tersebut dapat dicapai dengan melaksanakan pengukuran dan pengetesan dari pegas injektor. Pengetesan dapat dilakukan dengan pengujian tekanan minimum sampai tekanan maksimum dari pengabut bahan bakar, sehingga diperoleh hasil dari pengujian, apakah pegas masih dalam kondisi bagus atau harus dilakukan penggantian dengan yang baru.

3. Jarum Pada Pengabut Tidak Bergerak/Macet (Melekat Pada Rumahnya)

Jarum merupakan alat yang ada di dalam injektor berfungsi untuk memberikan jarak (kerapatan antara jarum dan rumahnya) terhadap bahan bakar yang akan masuk pada injektor. Tekanan

penyemprotan yang rendah memiliki tekanan kecepatan penyemprotan yang terlalu rendah pula sehingga mengakibatkan pengabutan yang kurang baik. Menurut hasil observasi penelitian, apabila jarum tidak bergerak maka jarum ini tidak bisa lagi bekerja sebagai pengabut bahan bakar, dikarenakan minyak dari pompa bahan bakar dengan tekanan banyak yang lolos melalui rongga antara jarum dan rumahnya, sehingga proses pengabutan tidak 
sempurna. Dapat juga akibat dari panas di dalam ruang pembakaran yang diterima rumah jarum akibat dari pembentukan sisa-sisa bahan bakar yang di dalamnya terdapat sisa pembakaran berupa kerak ataupun jelaga dan sisanya berupa kotoran. Kotoran inilah apabila ikut masuk ke dalam lubang pengabut yang berdiameter kecil dapat menghambat lubang tersebut, sehingga mengakibatkan jarum menempel pada rumahnya dan tidak bergerak. Jarum mempunyai tingkat kepekaan yang tinggi terhadap kotoran, sehingga sedikit saja di dalamnya terdapat kotoran akan menggangu kerja jarum sebagai pengabut bahan bakar. Pemeriksaan jarum harus dilakukan sebagai salah satu hal upaya untuk mencegah turunnya tekanan penyemprotan dari bahan bakar.

4. Tekanan Dari Pompa Injeksi Bahan Bakar Yang Menurun:

Pompa bahan bakar ialah pompa yang berfungsi mendistribusikan bahan bakar menuju injektor dan juga memberikan tekanan yang tinggi ketika masuk ke dalam injektor.

Pompa sebagai sistem penyalur bahan bakar disini mempunyai tekanan kerja yang berfungsi untuk memberikan tekanan pada bahan bakar sebelum masuk pada pengabut bahan bakar. Tekanan pompa bahan bakar yang ada di KM. BAHARI 12 antara 250-350 bar, dan dikabutkan oleh injektor dengan tekanan 280 bar bahwa penurunan tekanan dapat terjadi karena keausan pada plunyer, bocornya pipa tekanan tinggi, dan filter tersumbat kotoran".

Pada pompa banyak yang terjadi disebabkan keausan dan kerusakan pada plunyer, sehingga bahan bakar banyak yang lolos. Untuk mengembalikan kinerja 
pompa maka diharuskan pembongkaran. pengecekan, dan penggantian pada bagian- bagian pompa yang mengalami keausan tersebut. Hal ini berguna untuk mencegah turunnya tekanan dari bahan bakar yang akan dikabutkan injektor.

Dari hasil observasi yang didapat bahwa turunnya tekanan pompa dapat terjadi, karena beberapa hal: plunyer pada pompa telah mengalami keausan sehingga banyak bahan bakar yang lolos, salah pengaturan pada rack sehingga tekanan kerja yang dihasilkan tidak sesuai untuk pengabutan bahan bakar di dalam injektor, adanya kerusakan pada ring dari pompa bahan bakar. Dengan adanya kerusakan tersebut dapat diambil langkah perbaikan dan pembongkaran pompa bahan bakar guna meningkatkan kinerja pompa tersebut.

5. Lubang Nozzle Mengalami Kelonggaran/Terlalu Longgar

Pada bagian rumah lubang pengabut (bagian ujung pengabut) selalu mendapat panas yang tinggi dari hasil pembakaran di dalam ruang pembakaran (di dalam ruang silinder) dengan adanya perbedaan suhu yang terlalu tinggi, akan menyebabkan sekitar lubang-lubang pengabut mengalami ketegangan dan akan mengakibatkan keretakan bahan.

Dari hasil observasi yang dilakukan bahwa pemanasan ujung lubang nozzle bahan yang terjadi pada setiap pembakaran di dalam ruang silinder dapat mengakibatkan keretakan pada bagian lubang pengabut bahan bakar. Keretakan pada bagian ujung pengabut akan mempercepat pembesaran diameter lubang pengabut, disebabkan pengikisan oleh panas yang tinggi dan tekanan tinggi dari bahan bakar yang dikabutkan secara terus-menerus. 
Proses terjadinya pembesaran diameter lubang pengabut, karena pengisian bahan bakar dengan tekanan dan kecepatan yang tinggi dari pompa bahan bakar, oleh sebab itu akan mengakibatkan sudut pada lubang pengabut dan akan menyebabkan lebih besar pengikisan dari terbawanya kotoran-kotoran didalam bahan bakar yang diterima penutup jarum pengabut dan akan terangkat oleh karena tekanan dari bahan bakar pada permukaan bidangnya.

6. Pelaksanaan Perawatan Yang Tidak Melihat Petunjuk Instruction Manual Book.

Injektor ialah bagian dalam komponen mesin induk yang berfungsi mengabutkan ataupun mengatomisasi bahan bakar yang berasal dari pompa injeksi bahan bakar yang bertekanan tinggi serta untuk memberikan perubahan bentuk dari bahan bakar yang cair menjadi bentuk kabut dengan agar mudah terbakar dalam proses pembakaran di dalam ruang silinder. Disebabkan kerja yang berat dan berlangsung secara terus-menerus dari injektor, maka dibutuhkan adanya perawatan terencana dan rutin yang sesuai dengan Instruction Manual Book. Dengan melaksanakan perawatan terencana dan rutin akan mengurangi dan mengatasi menurunnya kinerja dari injektor serta untuk menghindari gangguan-gangguan yang ada pada pengabut bahan bakar.

\section{B. Upaya Yang Dilakukan Agar Kinerja Injektor Dapat Bekerja Secara Maksimal Dalam Pengabutan Bahan Bakar:}

Injektor ialah suatu alat yang digunakan sebagai pengabut bahan bakar di dalam ruang silinder ketika terjadi proses pembakaran dengan mengkompresikan bahan bakar tersebut. Dengan melihat vitalnya peran dari injektor di 
dalam sistem mesin induk maka pembuatan injektor dilakukan dengan menggunakan bahan-bahan yang sudah diuji keakuratannya dan berkualitas, untuk memperoleh kinerja injektor yang baik. Dengan demikian injektor dapat beroperasi dalam jangka waktu yang sudah ditentukan sesuai pengujian pada saat pembuatan oleh pabrik (maker). Semua alat pasti akan mengalami kelelahan bahan setelah digunakan dalam jangka waktu yang lama dan melampaui jam kerja seperti telah ditentukan oleh InstructionManual Book, maka apabila masih digunakan dapat mengakibatkan menurunnya kinerja dari injektor.

Untuk melihat dan mengetahui tentang menurunnya kinerja dari injektor pada saat melaksanakan pengabutan dapat dilakukan dengan pengambilan diagram indikator. Pengambilan dari diagram indikator dilakukan dengan menggunakan alat Indikator. Menurut hasil observasi di kapal, ada beberapa syarat yang harus dilakukan sebelum mengambil diagram indikator, antara lain:

1. Putaran dari mesin induk dalam posisi full ahead speed

2. Keadaan suhu dan tekanan berjalan normal

3. Kapal harus steady

4. Kapal keadaan even keel

5. Muatan harus penuh (full loaded) atau ada muatan di atas kapal.

Sedangkan Menurut P.Van Maanen,(1999), tentang pengambilan diagram indikator bahwa Untuk pengambilan suatu diagram, maka dipasang silinder torak dan pegas sehingga dihasilkan skala pegas yang dikehendaki. Torak dilumasi dengan beberapa tetes minyak pelumas. Pada tromol indikator ditempatkan selembar kertas indikator, pada umumnya berwarna merah, licin, dan dilapisi lapisan putih.

Menurut hasil observasi yang dilakukan, apabila semua 
syarat telah dipenuhi maka dapat dilaksanakan pengambilan diagram indikator. Cara pengambilan diagram indikator ialah sebagai berikut:

1. Sebelum pengambilan diagram indikator lakukan pembersihan udara yang dari lubang indikator guna menghilangkan jelaga dan kemudian tutup kembali.

2. Alat indikator dipasang pada indikator cock, dengan cara mengikat alat pengambil diagram indikator tersebut dengan katup silinder indikator, pada tromol ditempatkan kertas diagram dan pensil. Tali tromol diikat pada mesin penggerak.

3. Setelah itu buka katup indikator cock untuk menggerakkan alat tersebut, yang bekerja berdasarkan dorongan gas pembakaran dari dalam ruang silinder.

4. Ketika alat tersebut bekerja maka secara otomatis pensil yang diarahkan pada kertas diagram akan menggambar diagram indikator dari silinder yang diukur.

Pada setiap mesin induk selalu diambil diagram indikator guna mengetahui hasil pembakaran dan juga khususnya kinerja injektor dalam mengabutkan bahan bakar, ada kesalahan dimana injektor mengalami kesalahan pengabutan, antara lain:

a. Injektor mengalami keterlambatan pengabutan.

Keterlambatan dalam pengabutan bahan bakar sangat merugikan dalam proses pembakaran, oleh karena itu dapat diambil analisa hal-hal yang dapat mengkibatkan hal tersebut seperti analisa di bawah ini:

1) tekanan bahan bakar terlalu rendah

2) kerusakan pada katup bahan bakar

3) kerusakan pada katup isap pompa bahan bakar

4) pompa bahan bakar terlambat sedikit

b. Injektor mengabut terlalu cepat

Dalam penyemprotan bahan bakar juga bisa terjadi 
keadaan dimana bahan bakar mengabut terlalu cepat, sehingga waktu untuk mengabutkan tidak sesuai dengan keadaan kompresi, dan menyebabkan pembakaran kurang sempurna. Adapun analisa yang bisa dilihat ialah:

1) Tekanan bahan bakar terlalu besar

2) Injektor menetes.

Kualitas pembakaran dapat dipengaruhi oleh diameter dan ukuran lubang, injektor di kapal penulis melaksanakan penelitian menggunakan jenis banyak lubang(multi hole) yaitu terdiri dari 4 lubang yang berbeda diameter dari lubangnya. Dalam tiap lubang tersebut pasti mengalami perubahan diameter yang disebabkan oleh tingkat tekanan bahan bakar dan korosi bahan. Injektor ialah bagian yang sangat vital di dalam sistem mesin induk, sehingga secara langsung kinerjanya mempengaruhi dari kerja mesin induk. Oleh sebab itu untuk menjaga kinerja pengabut bahan bakar harus dilakukan upaya perawatan yang terencana dan rutin dengan melihat dari jam kerja, performa, dan kinerja pengabut bahan bakar. Upaya-upaya yang dapat dilakukan untuk mengoptimalkan kinerja pengabut bahan bakar diantaranya dapat dilakukan sebagai berikut:

\section{Pemeriksaan Dan Pengetesan Tekanan Kerja Injektor.}

Pemeriksaan dan pengetesan tekanan pada pengabut bahan bakar ialah salah satu metode dalam upaya meningkatkan kinerja injektor, pada pemeriksaan ini harus disesuaikan dengan petunjuk Instruction Manual Book agar dapat menghasilkan perawatan yang maksimal pada injektor. Hasil dari pemeriksaan dan pemeriksaan tekanan dari masing-masing silinder harus dicatat sebagai petunjuk untuk melakukan perawatan dan perbaikan yang akan dilakukan selanjutnya.

Adapun cara melakukan pengetesan tekanan kerja injektor dapat dilaksanakan sesuai dengan pedoman Instruction 
Manual Book seperti berikut:

a. Opening Pressure (Pengujian tekanan awal injektor)

Pada pengujian ini digunakan untuk mengetahui tentang tekanan awal yang dilakukan oleh pengabut bahan bakar. Apabila tekanan awal yang dilakukan tidak sesuai maka dapat dilakukan pengaturan dengan mengurangi atau menambah ring yang ada pada bagian bawah spring thrust spindle, akan tetapi bila ring tersebut sudah tipis harus dilakukan penggantian dengan yang baru, dan lakukan pengetesan lagi hingga sesuai dengan tekanan awal yang diinginkan.

b. Sealing Test (Pengujian tekanan pada needle valve seat)

Pengetesan ini dilakukan untuk mengecek needle valve seat sudah terikat kuat dan sudah tertutup rapat.Pengetesan ini dilakukan dengan menurunkan tekanan menjadi 15 bar dan setelah itu diturunkan lagi dengan cepat menjadi 0 bar, hal ini unk mengetahui dan melihat kemampuan needle valve dalam menerima tekanan kerja dari pengabut bahan bakar.

c. Pressure Test,O-Ring Sealing (Pengujian tekanan pada O-Ring)

Pengujian ini dilakukan untuk mengetahui kekuatan O-ring yang ada pada bagian katup sirkulasi minyak apakah baik atau tidak, dan juga untuk melihat apakah terjadi kebocoran pada sistem sirkulasi bahan bakar. Dengan cara membuka lubang sirkulasi tersebut dan memberikan tekanan awal 10 bar sampai ada minyak yang menetes, setelah itu tutup lubang tersebut dan masukkan O- ring, kemudian memberikan tekanan kerja maksimal sebesar 100 bar, lihat dan amati apakah ada kebocoran pada bagian O-ring tersebut.

d. Atomization test (tes pengabutan) 
Dari hasil penelitian didapat, ketika tekanan bahan bakar menjadi cukup tinggi maka keadaan katup akan terbuka sehingga bahan bakar akan mengabut. Pengabutan bahan bakar harus menyebar dengan teratur dan tidak boleh menetes. Pengabutan dipengaruhi oleh pergerakan dari jarum pengabut dan ketepatan dari pengaturan tekanan, jika lubang mulut pengabut ada yang tersumbat maka pengabutan akan kurang, jika kondisi jarum pengabut dan rumahnya tidak baik maka injektor akan menetes, apabila terjadi demikian maka injektor harus diatur kembali atau dengan mengganti nozzle.Setelah dilakukan pengujian sesuai dengan prosedur dan ternyata hasilnya tidak baik maka harus diadakan overhaul injektor dengan tujuan agar injektor dapat bekerja optimal kembali.

Menurut Instruction Manual Book bahwa pelaksanaan overhaul injektor meliputi:

a. Ukurlah terlebih dahulu panjang dari nozzle injektor dan tulis pada Record Book, sebagai catatan saat pemasangan kembali.

b. Letakkan injektor pada alat pemegang injektor, naikkan injektor pada pegangan alat, dan sesuaikan dengan dudukan mesin penekan.

c. Tekan injektor dan pegas yang ada di dalam dengan mesin bor, untuk menghindari injektor terpisah bagian-bagiannya. Lepas mur yang mengikat bagian atas dan bawah injektor dengan kunci gantung (hook spanner).

d. Ambil valve head dari rumah injektor, keluarkan Non return valve, thrust spindle parts, thrust foot, dan spindle guide juga nozzle dari rumah injektor. Juga keluarkan $O$-ring.

e. Bersihkan dan uji bagian dari injektor seperti: rumah injektor, fuel valve head, dan thrust spindle, 
lakukan penyekiran pada

1) Bagian dalam bawah pada rumah injektor.

2) Bagian samping dari kepala injektor

3) Atas dari non return valve.

f. Lakukan penyekiran dengan cara manual untuk mendapatkan hasil yang baik.

g. Lakukan pembersihan dan pengujian pada nozzle injektor. h. Pembongkaran dan pengujian pada non return valve.

i. Setelah selesai pembongkaran, masukkan lagi bagian: thrust foot, bagian dari thrust spindle, dan non return valve pada rumah injektor.

j. Gunakan O-ring yang baru pada setiap bagian injektor.

k. Tekan dengan mesin bor dan ikat mur yang menghubungkan bagian atas dan tengah dari injektor. Lakukan pengetesan injektor.

Dari hasil observasi penelitian didapat langkahlangkah dalam melakukan overhaul injektor:

a. Meletakkan injektor pada overhaul stand kemudian kencangkan baut dan murnya (untuk lebih jelasnya lihat lampiran gambar )

b. Ukur panjang ujung nozzle dan catat hasil pengukuran untuk pemasangan kembali.

c. Kendorkan cap nut dengan kunci khusus, saat dilepas maka nozzle juga akan ikut terlepas.

d. Tarik bagian Valve head dari body injektor untuk langkah awal.

e. Lepas seluruh bagian dalam dari injektor yang meliputi spindle guide, non return valve, thrust foot, dan nozzle bahan bakar.

$f$. Jangan lupa keluarkan seluruh O-ring pada setiap bagian injektor

g. Setelah itu bersihkan seluruh bagian-bagian dari 
injektor dengan menggunakan solar sampai bersih satu persatu bagian injektor.

h. Bersihkan nozzle injektor bagian luar dengan menggunakan mesin wire brush untuk menghilangkan kerak yang menempel.

i. Bersihkan lubang-lubang nozzle injektor dengan menggunakan kawat yang diameternya lebih kecil dari lubang nozzle untuk menghilangkan kerak yang ada di dalam lubang pengabut.

j. Mengadakan pemeriksaan terhadap pegas (spring) penekan jarum, perhatikan daya renggangan dari pegas, jika sudah mengalami keausan diadakan penggantian dengan yang baru.

k. Periksa dan perhatikan diameter lubang pengabut bahan bakar,apabila lubang diameter nozzle telah bertambah lebar lakukan penggantian dengan yang baru.

1. Periksa dan perhatikan kondisi nozzle dari keausan kemudian lihat tanda-tanda korosi. Korosi asam sulfur terjadi karena suhu pendingin pada injektor terlalu rendah. Jika kondisi jarum dan rumah pengabut sudah aus maka harus di skir (lapping) menggunakan pasta (carboruhdum paste).

m. Setelah itu pasang kembali semua komponen injektor dan melakukan pengetesan.

\section{Pengecekan Bahan Bakar}

Kualitas dari bahan bakar sangat berpengaruh terhadap terjadinya kerusakan pada lubang pengabut karena kotoran yang menyumbat sehingga proses pengabutan kurang sempurna. Kandungan yang ada dalam kandungan bahan bakar salah satunya ialah belerang. Menurut P.Van Maanen, (1999), tentang"bahan bakar cair mengandung belerang yang tinggi sebagai molekul terikat $\mathrm{C}-\mathrm{H}$ sehingga tidak dapat dipisahkan. Kadar 
belerang sangat penting mengingat timbulnya korosi pada suhu rendah dari bagian motor karena pendinginan dari gas pembakaran".

Dari hasil observasi, kurang bagusnya kualitas bahan bakar di kapal disebabkan oleh banyak kandungan kotoran yang ada dalam bahan bakar, dapat dilihat dari seringnya penyumbatan-penyumbatan pada saringan bahan bakar oleh karena kotoran seperti lumpur. Biasanya pembersihan bahan bakar dikapal dilaksanakan secara bertahap, sehingga hasilnya akan lebih sempurna. Jika tidak dilaksanakan secara bertahap pembersihan bahan bakar tidak dapat berjalan dengan baik. Bahan bakar yang kotor dapat dipengaruhi oleh:

a. Filter ( Saringan) yang kotor

Dengan bantuan saringan dapat dipisahkan kotoran padat dari bahan bakar cair dan bahan pelumas, dalam hal ini digunakan perbedaan dalam kondisi agresasi.Sebagai akibat dalam tegangan permukaan antara minyak dan air, maka pada lapisan penyaringan akan dipisahkan juga bagian air yang kecil. Dari hasil observasi penelitian, dalam hal ini saringan yang sering digunakan ialah saringan permukaan dengan bahan saringan berupa kasa metal dan lamel metal. Dalam prosesnya penyaringannya bahan saringan sebagai filter kotoran agar tidak lolos langsung menuju ke permesinan bantu yang ada pada jalur sistem bahan bakar. Sehingga saringan (filter) dapat membantu menjaga kualitas bahan bakar yang baik.

b. Pengecekan bahan bakar sebelum bunker

Pengecekan kadar yang terkandung dalam bahan bakar sangat mutlak dilakukan pengujian sebelum dilakukan proses bunkering, untuk mengetahui kualitas bahan bakar dan juga memenuhi beberapa persyaratan spesifikasi beberapa sifat bahan bakar.

c. Pembersihan tangki-tangki penyimpanan bahan bakar, dan masukan FOT (fuel oil treatment) kedalam 
tangki penampungan awal sesuai petunjuk.

Dari hasil observasi perawatan tangki-tangki penyimpanan biasanya dilakukan setiap 2 bulan sekali, atau sebelum dilakukan pengisian bahan bakar. Langkah ini dilakukan untuk membersihkan endapan kotoran-kotoran yang ada pada tangki bahan bakar terutama pada tangki settling. Perawatan dengan menggunakan cairan kimia digunakan untuk menjaga kualitas bahan bakar.

\section{Pemanasan bahan bakar dengan heater}

Pemanasan ini dipergunakan untuk memanaskan bahan bakar MFO, karena bahan bakar ini bersifat mudah mengental maka perlu dipanaskan agar kandungan belerang di dalam bahan bakar tidak menjadi asam yang mengakibatkan bisa timbulnya terjadinya korosi.

Dari hasil observasi didapat bahwa fungsi dari pemanasan bahan bakar ialah untuk mendapatkan nilai viskositas atau kekentalan dari bahan bakar, karena apabila bahan bakar yang akan dikabutkan terlalu kental maka akan sulit untuk dikabutkan dan juga akan mengurangi tingkat tekanan kerja dari bahan bakar. Nilai pemanasan di dalam heater berkisar antara $80-90^{\circ} \mathrm{C}$.

\section{Fuel Injection Pump}

Pada tanggal 15 Maret 2015 di kapal MT.TIMUR LAUT MAS pada saat kapal berlabuh di Tanjung Priok di Jakarta terjadi kerusakan di dalam cylinder liner no 3 setelah di cek pada injektornya ternyata injektor masih bekerja dengan baik setelah di tes menggunakan injector tester, setelah itu di cek pada injection pump ternyata terjadi kerusakan pada plunger injection pump sehingga sebagian besar bahan bakar lolos mengakibatkan pengabutan bahan bakar kurang sempurna dan berpengaruh pada daya main engine, 
meskipun tekanan injektor baik namun jika tekanan pompa injeksi bahan bakar (injection pump) turun maka injektor tidak akan bisa mengabutkan bahan bakar dengan baik. Tekanan yang kurang akan mempegaruhi penyemprotan bahan bakar kedalam ruang pembakaran.

Menurut P.Van Maanen, (1999), bahwa "Untuk pengabutan yang baik dari bahan bakar diperlukan kecepatan penyemprotan yang tinggi (250-350 $\mathrm{m} /$ det), untuk pengabutan langsung dan penyemprotan tinggi tersebut dicapai dengan tekanan pengabutan tinggi (hingga 1000 bar).

Sehingga dengan turunnya tekanan pompa bahan bakar yang kurang akan secara langsung mempengaruhi proses pengabutan dan penyemprotan bahan bakar dari injektor menuju ke ruang silinder.

Untuk mengetahui apakah plunyer dan silinder barrel masih dapat berfungsi dengan baik atau tidak dapat dilakukan dengan pengetesan secara sederhana sebagai berikut : Silinder barrelnya dipegang dengan tangan kiri dengan keadaan ibu jari menutup lubang pemasukan minyak solar dan jari tengah menutup lubang limbah sedangkan jari telunjuk jari telunjuk menutup lubang pengelutaran minyak solar atau lubang yang berhubungan dengan dudukan klep deliveri. Selanjutnya masukkan plunyer kedalam silinder barrel sampai menyentuh jari telunjuk. Secara serentak ketiga jari tangan kiri menutup ketiga lubang, kemudian plunyer ditarik oleh tangan kanan, kemudian lepaskan. Jika plunyer secara spontan kembali seperti semula (seperti sebelum ditarik) berarti plunyer dan silinder barrel masih dalam keadaan baik. Tetepi jika kembalinya plenyer terjadi pelan-pelan berarti plunyer dan silinder barrel nya sudah tidak baik.

Upaya yang perlu dilakukan apabila tekanan pompa bahan bakar rendah:

1. saluran pengeluaran bila terdapat kotoran bersihkan. 
2. Pada Bersihkan mengunakan solar.

3. Setelah itu semprot dengan udara bertekanan.

4. Keringkan dengan menggunakan majun, dan jangan sampai ada serat yang tertinggal.

5. Pegas pasak, pegas katup periksa kerenggangan apakah masih dapat menekan dengan baik.

6. Pada silinder plunyer dan plunyer lakukan pembersihan bila terjadi keausan pada plunyer lakukan penggantian.

7. Pada batang pengatur bahan bakar bila terjadi kemacetan berikan pelumasan .

a. Pada batang pengatur lakukan pembersihan pada batang pengatur.

b. Pada saat pemasangan berikan pelumasan.

c. Jika sudah rusak lakukan penggantian.

Komponen pada injection pump yang sering mengalami kerusakan dan cara perbaikannya:

a. Plunger

Penyebab kerusakanya: pemakaian bahan bakar yang berkontaminasi dengan bahan bakar lain adanya kotoran yang mengendap pada tangki bahan bakar, saringan bahan bakar yang tidak bekerja dengan baik (lama tidak di ganti) Cara perbaikanya: bersihkan tangki bahan bakar atau ganti saringan bahan bakar dan ganti plunger denga yang baru.

b. Delivery Valve

Penyebab kerusakannya: delivery valve yang aus dikarenakan injection pump memiliki tekanan bahan bakar yang sangat tinggi dan pemakaian yang telah lama maka katup pembagi ini akan aus akibat fungsi kerjanya untuk menekan tekanan yang di hasilkan.

Cara perbaikannya: delivery valve ini bila terjadi keausan maka perbaikannya dengan di ganti dengan yang baru.

c. Bearing

Penyebab kerusakannya: bearing yang aus di karenakan 
adanya getaran putaran kejut saat injection pump beroperasi.

Cara perbaikannya: jika terjadi pada bearing ganti bearing dengan yang baru.

d. Sliding Block

Penyebab kerusakannya: mengatur keluarnya bahan bakar yang memiliki gigi-gigi pinion yang berhubungan dengan plunger barrel, jika pemakaiannya telah lama gigi nya akan aus.

Cara perbaikannya: ganti dengan yang baru.

e. Busing Gas Stang

Penyebab kerusakannya: karena telah lama dipakai dan adanya gesekan dengan as stang gas maka busing tersebut aus.

\section{KESIMPULAN}

Berdasarkan hasil pembahasan maka penulis mengambil beberapa kesimpulan yang berhubungan dengan peningkatan kerja dari injector dan injection pump sebagai berikut:

1. Penyebab kurang optimalnya kinerja injector dalam pengabutan bahan bakar, meliputi: terjadi penyumbatan kotoran pada lubang nozzle, pegas(spring) penekan jarum tidak bekerja, jarum dari pengabut tidak bergerak atau macet, tekanan injeksi bahan bakar yang turun, lubang nozzle telah longgar, dan kurang optimalnya kinerja injection pump di sebabkan oleh plunyer yang sudah aus, bearing yang sudah aus, delivery valve yang sudah aus, bocornya pipa tekanan tinggi, filter tersumbat dan perawatan yang tidak sesuai Instruction Manual Book.

2. Upaya pengoptimalan kerja injector dan injection pump dilakukan dengan : pengambilan diagram indicator, melakukan pengujian tekanan injector, 
melakukan pengecekan kualitas bahan bakar, pengecekan kerja purifier, pengecekan kerja injection pump.

\section{DAFTAR PUSTAKA}

C. C pounder. 1972. Diesel Motor Engine and Machinery Drawning. Copenhagen.

Jusak. 2009. Perawatan dan Perbaikan Permesinan kapal. Jakarta :BP3IP Jakarta.

L Maleev. 1991. Operasi dan Pemeliharaan Mesin Diesel. Penerbit: Erlanggan. P. Van Maanen. 1990. Motor Diesel Kapal.PT. Triakso Mandra: Jakarta 